\title{
Up periscope: understanding submarine command and control teamwork during a simulated return to periscope depth
}

\author{
Neville A. Stanton ${ }^{1} \cdot$ Aaron P. J. Roberts ${ }^{1} \cdot$ Daniel T. Fay $^{1}$
}

Received: 19 April 2017/ Accepted: 1 June 2017/Published online: 8 June 2017

(c) The Author(s) 2017. This article is an open access publication

\begin{abstract}
A submarine is routinely required to return to periscope depth; however, a transition from deep to shallow waters is one the most dangerous operations due to the potential to collide with surface vessels. Submarine operations are not particularly well understood outside the immediate submarine community, particularly from a sociotechnical perspective. A submarine sounds and control room simulator was used to examine the work of ten teams. The Event Analysis of Systematic Teamwork method was used to model the social, task and information networks in order to describe team performance. Results showed that the sonar controller and operations officer are the busiest in the command team. Communication between these operators was revealed as a potential bottleneck in the command team, particularly during higher demand scenarios. The information communicated and tasks completed centred on the processing and understanding of sonar data. Implications are discussed alongside suggestions for future work.
\end{abstract}

Keywords Submarine - Command and control . Teamwork $\cdot$ Communications $\cdot$ Networks $\cdot$ EAST

Neville A. Stanton

n.stanton@soton.ac.uk

1 Human Factors Engineering, Transportation Research Group, University of Southampton, Building 176, Boldrewood Innovation Campus, Burgess Road, Southampton SO16 7QF, UK

\section{Introduction}

\subsection{Sociotechnical systems-control rooms}

A sociotechnical system involves the interaction of human operators and technology, with interdependence to pursue broader goal-directed behaviours creating the conditions for successful overall performance (Walker et al. 2008, 2009). Control rooms are found in numerous other domains, such as aviation, chemical, energy production and distribution, defence, healthcare, manufacturing, nuclear, oil and gas and security (Stanton et al. 2010). Their commonality is a reliance upon effective communication and teamwork (Stanton et al. 2003). Such processes can be the determining factor in terms of team workload rather than the work itself (Salas et al. 2001; Stanton 2011; Salas et al. 2001; Carletta et al. 2000). A major challenge when optimising the design and operation of rooms in general is that they are complex by nature and as a result knowledge is not easily attained and shared by operators, manufacturers and researchers alike (Stanton et al. 2010). This is compounded by the fact that control rooms in many domains manage hazardous systems and are often subject to heightened security and regulation (Roberts et al. 2015).

In sociotechnical systems effective sharing of information is critical as cognitive processes and situation awareness are not held by one agent or individual but rather are distributed across the control room (Stanton 2014, 2016; Stanton et al. 2017; Read et al. 2015). Understanding how information is distributed and shared within command teams can facilitate the optimal design of control rooms and technologies (e.g. interfaces) within them across many domains (Stanton 2011, 2014; Salas et al. 2001; Lee and Kantowitz 2005). The manner in which a team is configured and how technology supports communication can also influence their 
effectiveness (Stanton et al. 2015a, b; Espevik et al. 2006). Understanding how processes and tasks are completed within the sociotechnical system and how situation awareness (SA) is maintained is a key challenge for facilitating the design of future control rooms in many domains (Stanton 2014, 2016; Stanton et al. 2017).

\subsection{Submarine command and control: returning to periscope depth}

A submarine control room requires effective interaction between numerous technological and human agents for optimal performance and maintenance of safety. As such it is an excellent example of a complex sociotechnical system (Shattuck and Miller 2006; Stanton 2014). A primary role of submarines is to operate well below 'safe' depths (i.e. $60 \mathrm{~m}$-which is below the hull of the deepest supertanker). Submarines undertake numerous duties including (but not limited to): costal protection, intelligence collection and scientific research (Stone et al. 2009; Bateman 2011). Whilst there are tactical advantages of operating deep (particularly to remain covert), periodically submarines are required to return to periscope depth, which is approximately $20 \mathrm{~m}$ from the surface (Bateman 2011). A transition from deep to shallow waters is arguably one of the most dangerous of the routine operations completed by submarines, with potentially catastrophic consequences if it collides with a surface vessel (Drumheller and Benoit 2004). The submarine control room has evolved across decades and so represents a highly advanced system, but that does not mean that it cannot be improved (Stanton 2014).

The submarine predominantly relies on passive sonar to maintain awareness of surrounding vessels and avoid collisions with surface vessels as shallower depths are achieved (Shar and Li 2000). Passive sonar is useful for the detection of vessels near the submarine, particularly when remaining covert is a key requirement. Nevertheless, the accuracy of such sensors can be greatly affected by background noise (e.g. multiple vessels) and oceanographic conditions (Zarnich 1999; Ogden et al. 2011). A submarine command team is required to process and interpret passive sonar data to provide awareness of where the submarine can return to periscope depth whilst maintaining the safety of the crew and other vessels (Jones et al. 2011). Technological advancements have improved sensor and algorithmic capabilities, but this does not necessarily mean that such advancements are effectively integrated and/or utilised to optimise performance (Dominguez et al. 2006; Roberts et al. 2015).

A submarine is equipped with numerous sensors, instruments and interfaces that must be used by a team of operators to support the Commanding Officer's (CO) tactical decision making. Understanding how each part of the sociotechnical system contributes to global mission objectives is a challenge (Loft et al. 2013; Stanton and Bessell 2014; Huf et al. 2004). Even the CO is not explicitly aware of the large amount of data processing completed by individual operators to provide a tactical picture from which decisions can be made (Dominguez et al. 2006; Stanton et al. 2006). The warfighting capabilities (Hunter et al. 2014), track management assessment (Loft et al. 2013) and tactical decision making problem spaces (Dominguez et al. 2006; Mansell et al. 2003; Chalmers 2010) of submarine command teams have been examined. However, none of these studies have examined multiple teams. A challenge for team-based research is to conduct studies with good statistical power to provide evidence for where improvements in control room design should be targeted.

A sociotechnical perspective of how a submarine return to periscope depth has been provided in previous work, when examining an operational command team during training (Stanton 2014; Stanton and Bessell 2014). The descriptive power of such work has greatly informed understanding of how information flows around the submarine control room. This work has helped to identify critical information in the command team and the tasks that are completed (Stanton 2014). In this work only one command team was examined, so team variances are unknown (Stanton et al. 2008). A challenge for submarines of the future is adapting to greater variability in demand due to increasing numbers of vessels in the water, both surface and submerged, coupled with a shift in the primary location of submarine operation completion to coastal littoral zones (Bateman 2011; Duryea et al. 2008). It is important to understand how a submarine return to periscope depth in conditions of both high and low-demand (e.g. varied number of contacts), to inform the design of adaptive, flexible control rooms that are optimal for different task loads.

Our work seeks to extend understanding of return to periscope depth operations from a sociotechnical perspective to identify potential weaknesses in current submarine control room design and suggest future design considerations for control rooms in general. A further aim is to examine multiple command teams to provide firm empirical validation of findings, something typically lacking from team-based research. The work shall also examine the effect of different levels of task demand on team strategies to facilitate understanding of the (non-) static nature of control rooms.

\section{Method}

\subsection{Participants}

Ten teams of 8 individuals ( 80 participants in total) were recruited by contacting local groups with a maritime or 
military interest (e.g. military-sponsored undergraduates, defence organisations and companies and Royal National Lifeboat Institute). A total of 71 males and 9 females participated with an age range of $18-55$ (mean $=26.83$, $\mathrm{SD}=8.69$ ) from a variety of backgrounds. One team were submariners from the British Royal Navy. Participation in the study was voluntary. The roles they fulfilled, as described in Table 1, were: Sonar Operator (SOP), Target Motion Analysis (TMA), a Sonar Controller (SOC), Operations Officer (OpsO), Periscope (PERI), Ship Control station (SHC) and Officer of the Watch (OOW). The study protocol received ethical approval from the University of Southampton Research Ethics Committee (Protocol No: 10099) and MoDREC (Protocol No: 551/MODREC/14).

\subsection{Equipment-The Submarine control room simulator}

A submarine control room simulator (see Fig. 1) was built based upon a currently operational Royal Navy (RN) submarine control room (for full description see Roberts et al. 2015). The simulator engine used was Dangerous Waters (DW), a software package developed by Sonalysts Combat solutions. The simulator was equipped with a comprehensive recording suite (e.g. web cameras and ambient microphones) which allowed the recording of all communications that occurred between operatives. The simulator was comprised of 9 networked workstations which included two Target Motion Analysis stations (TMA), two Sonar Operator stations (SOP), an Operations Officer station (OpsO), a Sonar Controller station (SC), a Ship Control station, a Periscope station and an Officer of the Watch station (OOW). The choice of stations was informed by Subject matter Experts (SMEs) from the RN to be representative of a currently operational control run. SMEs also informed the design of lower and higher demand return to periscope depth (RTPD) scenarios (see Table 2); each scenario lasted approximately $45 \mathrm{~min}$, and the behaviour of 'contact' vessels was predetermined.

\subsection{Design}

The study employed a $2 \times 9$ mixed design (social networks), a $2 \times 14$ repeated measures design (information networks) and a $2 \times 12$ repeated measures design (task networks). The independent variables were scenario demand (within subjects), operator role (between subjectssocial network), information type (within subjects-information network) and task type (within subjects-task network). A $1 \times 2$ within-subjects design was used to examine overall network composition of the social and information networks. Scenario demand was manipulated by adjusting the number of contacts detectable in the scenario and their behaviour (see Table 2). The dependant variables included all communications that took place between operators within the command team and tasks completed.

\subsection{Procedure}

Participants attended the simulator facility for two full days from 8 am to $5 \mathrm{pm}$. On the first day (training) participants signed a consent form, simulator induction was performed, and operator roles were randomly assigned. Participants then spent the morning watching the first 3 video tutorials as a group, and each tutorial lasted approximately $45 \mathrm{~min}$ (see Table 3 for a description of tutorials). In between tutorials the experimenters encouraged questions regarding

Table 1 Overview of roles and main duties

\begin{tabular}{|c|c|}
\hline Role & Overview of main duties \\
\hline OOW & $\begin{array}{l}\text { Responsible for directing submarine activity, interpreting the tactical picture to manoeuvre the submarine effectively to best complete } \\
\text { mission objectives whilst simultaneously maximising submarine safety and covertness }\end{array}$ \\
\hline OPSO & $\begin{array}{l}\text { Co-ordinate the generation of a tactical picture based upon OOWs requests. Direct and quality check the work of the TMAs and } \\
\text { Facilitates the flow of information from the sound room (via SOC), to the relevant TMA operator. Pass visual information (via PERI) } \\
\text { to the TMAs to generate contact solutions }\end{array}$ \\
\hline SOC & $\begin{array}{l}\text { Co-ordinate activity in the sound room and responsible for the integration of all sonar data from multiple arrays. Direct and quality } \\
\text { check the work of the SOPs. Facilitate the flow of relevant information from the sound room (via OPSO) to the picture room }\end{array}$ \\
\hline SOP & $\begin{array}{l}\text { The SOPs are required to sweep the sonar arrays (visually and aurally) to detect potential contacts, seek permission (from SOC) to } \\
\text { designate contacts and perform analysis of acoustic data to classify (via narrowband) and generate speed estimates (via DEMON) of } \\
\text { contacts. Typically each SOP will operate a different sonar array }\end{array}$ \\
\hline TMA & Generate contact solutions (predict behaviour of contacts) by analysing patterns of acoustic or visual bearing cuts \\
\hline PERI & Operating periscope and gathering visual information regarding surrounding contacts and any other intelligence (e.g. land-based objects) \\
\hline SHC & $\begin{array}{l}\text { The SHC responds directly to orders from OOW and must be aware of submarine safety and covertness. Enacting and overseeing } \\
\text { changes to own submarine parameters (e.g. course, speed and depth) }\end{array}$ \\
\hline
\end{tabular}



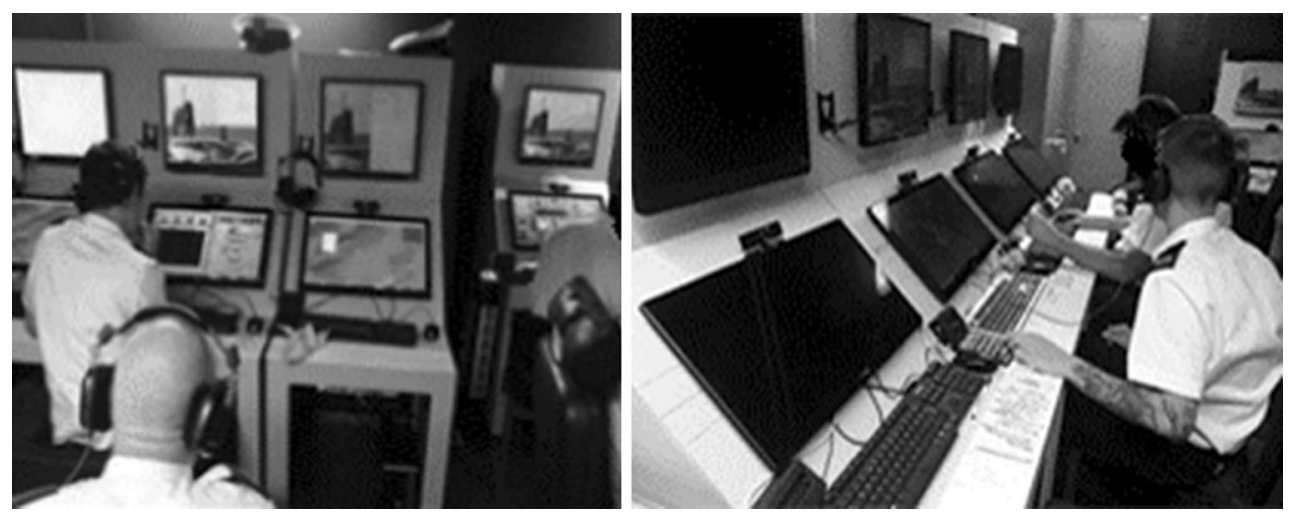

Fig. 1 The ComTET submarine control room simulator, with sound room on the left and picture room on the right

Table 2 Description of scenarios

\begin{tabular}{llll}
\hline Scenario & Demand & No. contacts & Mission \\
\hline $\begin{array}{c}\text { Return to periscope } \\
\text { depth (RTPD) }\end{array}$ & Low & 4-Fishing & $\begin{array}{c}\text { RTPD from deep to send intelligence home, large temporal window of opportunity. All } \\
\text { contacts held must be ranged to find optimum course for RTPD. Scenario complete } \\
\text { once periscope has marked all contacts } \\
\text { RTPD as quickly as possible due to submarine damage. Attempt to range all contacts to } \\
\text { find optimum RTPD course }\end{array}$ \\
& High & $\begin{array}{l}\text { 9-Fishing } \\
\text { 3-Catamaran } \\
\text { 1-Biological }\end{array}$ & \\
\hline
\end{tabular}

tasks and how the command team performed, a 15-min break was provided between each tutorial. Participants then completed an 'anagram game' which brought together all aspects of the morning training session. Participants were then given a 45-min lunch break.

In the afternoon participants received tutorials specific to the workstation they had been assigned. Participants were sat at their relevant workstation and had the tutorial running on a top screen and a training version of their workstation interface on the bottom screen. This allowed participants to pause aspects of the tutorial and practice task completion interactively. The afternoon was spent completing practice training sessions $(1 \mathrm{~h})$ at individual workstations with help from the experimenters. The final part of training was dedicated to completing practice RTPD scenarios as a command team.

On the second day participants attended the simulator and immediately completed a refresher training scenario as a command team. Participants then completed both the low and high-demand RTPD testing scenarios. To prevent order effects the presentation order of scenarios was counterbalanced across teams. Participants were told that the first scenario would begin-all recording devices were started and a verbal time stamp was read aloud for synchronisation purposes. Each scenario began with an OOW briefing outlining the mission objectives (see Table 2). Once the command team had completed the mission objective the end of the scenario was called, after a short break for refreshments and debrief regarding the previous scenario participants were asked to sit back at their workstation and the second scenario would begin.

\subsection{Analysis of data}

The analysis of data used a new shortened form of Event Analysis for Systemic Teamwork (EAST: Stanton et al. 2008). This approach has been used previously to model submarine command and control (Stanton 2014), and other domains including aviation (Stewart et al. 2008; Stanton and Harvey 2016), naval warfare (Stanton et al. 2009) and emergency services (Houghton et al. 2006). Three types of networks are derived from the raw data of video and audio recordings of communications within the command team. Social networks analyse the communications taking place between the 'agents' working in the team. Information networks describe the information that the different 'agents' use and communicate during task performance. Finally, task networks describe the relationships between tasks, their sequence and interdependences. These networks were processed using AGNA software (version 2.1.1 - a software program for computing the Social Network metrics - see Table 4). The audio recordings were transcribed, and a frequency count of communications between agents was compiled in adjacency matrices for 
Table 3 Description of tutorial training package

\begin{tabular}{ll}
\hline Tutorial & Description \\
\hline Submarine command & $\begin{array}{l}\text { Introduction to the submarine simulator, the operator } \\
\text { roles, the different sensors on board a submarine and } \\
\text { the command structure within a submarine command } \\
\text { team }\end{array}$
\end{tabular}

Introduction to bearing, speed, course and range

Describing the basics of bearing, speed range and course in relation to own submarine and to contacts that might be surrounding the submarine. Describing passive sonar and how information concerning speed can be derived from analysis of sound

\author{
Military communication \\ protocol
}

Anagram communication game

(3 game trials)

Workstation tutorial (Sonar, TMA, Periscope and SHC)

Practice workstation free play

Command team tutorial

Practice RTPD scenario completion

\section{Purpose}

Develop basic understanding of what a submarine command team does, what type of data is received, what the operator roles are

Develop an understanding that using passive sonar to create a tactical picture requires the interpretation of ambiguous information. Understanding that the only definite information is the bearing at which contacts are heard and that acoustic signature processing can provide 'estimates' of speed

It was important to examine command team functionality with a level of fidelity that was comparable to operational procedures. The communication protocol in the military is clearly defined, and it was important for operators to pass information in a manner comparable to operational teams

This brought together the morning training session. It allowed participants to understand that they may all be completing different tasks and contributing different pieces of information to facilitate the generation of an overall tactical picture. It allowed participants to practice operating as a command team without the complexities of the domain

To develop an understanding of the particular tasks completed by each individual within the command team. This tutorial was completed very much at the level of the individual with a focus on manipulating the interface for procedural task completion.

Examples include how to spot a contact on sonar, how to listen to a contact, how to designate a tack ID on sonar

Participants could speed up time. This allowed participants to work at their own pace. The purpose of this part of the training was to allow participants to complete all of the task that they would be expected to complete in the command team, without command team pressures. Participants could restart scenarios multiple times and speed up time, allowing a focus on the tasks and procedures they felt needed the most attention

This part of the tutorial brings together the communication game, which taught participants the command structure and communication protocol. Instead of using anagrams as data, participants were now made aware of the tasks and data they were responsible for and which members of the command team need this information to generate a tactical picture

At this point participants were accomplished at completing the procedures and tasks at their own workstations. The final training session pulled together everything that had been learnt throughout the day. This included completing tasks at their workstation, passing relevant output (data) to members of the command team 
each team. The nodes in the information networks were determined using Leximancer software (version 2.1-a software program for identifying concepts in text documents), the top 14 information elements (according to frequency count) were included in the statistical analysis of the information nodes. The task nodes were derived by watching the videos and listening to audio to ascertain when a particular task was performed. The task networks were verified by SMEs before frequency counts were completed.

A number of metrics can be acquired via AGNA to facilitate the quantitative assessment of the networks including global network metrics (e.g. density, diameter and cohesion) and individual nodal metrics (e.g. sociometric status and centrality of each node-see Table 5). A description of network typology is provided in previous work (Stanton 2014). The data were assessed to check if met the requirements (e.g. distribution and homogeneity) for parametric analysis to be conducted. When examining network nodes the effect of scenario demand and operator role (social network metrics) were analysed by completion of a $2 \times 8$ mixed analyses of variances (ANOVA). A $2 \times 14$ repeated measures ANOVA was conducted to examine the effect of scenario demand and information type (information network metrics). To examine the effect of demand on entire network composition paired $t$ tests were conducted to examine both social and information networks. The nodes and composition of the task networks were not examined as the composition of the task networks was the same during the high and low-demand scenarios across all teams. However, a $2 \times 12$ repeated measures ANOVA was conducted to examine the impact of demand on task completion frequency (task network metrics). All significant main effects were examined by conducting post hoc pairwise comparisons. To account for multiple post hoc comparisons the Bonferroni correction method was used ( $\alpha=0.05 /$ number of comparisons). All statistical analyses were conducted using IBM SPSS v21.

Table 4 Global network metrics

\begin{tabular}{ll}
\hline Metric & Definition \\
\hline Nodes & $\begin{array}{c}\text { Number of entities in a network (people, information or } \\
\text { tasks for the purposes of this paper) }\end{array}$ \\
$\begin{array}{l}\text { Edges } \\
\text { Dumber of pairs of connected entities }\end{array}$ & $\begin{array}{c}\text { Number of relations observed represented as a fraction of } \\
\text { the total relations possible } \\
\text { Cohesion }\end{array}$ \\
$\begin{array}{c}\text { Number of reciprocal connections in the network divided } \\
\text { by the maximum number of possible connections }\end{array}$ \\
Diameter & $\begin{array}{c}\text { Number of hops required to get from one side of the } \\
\text { network to the other }\end{array}$ \\
\hline
\end{tabular}

\section{Results}

\subsection{Social network analysis}

The average frequency of communications between operators in the command team varied depending on command team role and scenario demand (see Fig. 2). OPSO and SOC had the largest volume of emissions and receptions of all operators. The overall composition of both networks is similar; however, the volume of interactions between operators appears to increase during the high-demand RTPD scenario.

\subsection{Global social network metrics}

A non-significant trend was observed $\left(t_{9}=-2.12, p=.06\right.$, $d=0.67)$ for an increase in the total number of emissions and receptions in the high-demand RTPD condition. This means that there were more interactions in the high-demand scenario, as to be expected. No other statistically significant effects were observed, indicating the structure of the network remained relatively consistent in both higher and lower demand conditions (see Table 6).

\subsection{Nodal social network metrics}

The main effects of demand, role and interaction between demand and role are presented in Table 7. Overall, emissions, receptions and the sociometric status of nodes statistically significantly increased $(p<.05)$ whilst eccentricity statistically significantly $(p<.05)$ decreased in the high-demand RTPD scenarios compared to the lowdemand RTPD scenarios. The post hoc statistical analysis of significant effects is described below.

Table 5 Nodal network metrics

\begin{tabular}{ll}
\hline Metric & Definition \\
\hline $\begin{array}{l}\text { Emission } \\
\text { Reception }\end{array}$ & $\begin{array}{l}\text { Number of links emanating from node in the network } \\
\text { network }\end{array}$ \\
Sociometric & $\begin{array}{l}\text { Number of emissions and receptions relative to the } \\
\text { number of nodes in the network }\end{array}$ \\
Centrality & $\begin{array}{l}\text { The sum of all distances in the network divided by the } \\
\text { sum of all distances to and from the node }\end{array}$ \\
Closeness & $\begin{array}{l}\text { Inverse of the sum of the shortest distances between } \\
\text { each individual and every other person in the network }\end{array}$ \\
Farness & $\begin{array}{c}\text { Sum of each node to all other nodes in the network by } \\
\text { the shortest path } \\
\text { Number of times a node lies on the shortest path } \\
\text { between other nodes }\end{array}$ \\
Eccentricity & $\begin{array}{l}\text { The number of relations in the shortest possible } \\
\text { distance from node actor to another }\end{array}$ \\
&
\end{tabular}


Fig. 2 Social network diagrams for low (2a) and high (2b) demand RTPD scenario. The lines indicate the average number of emissions and receptions between operators in the command team (weighted lines reveal stronger connections). The diagrams reveal a potential bottleneck in information flow between SOC and OPSO, particularly in the high-demand scenario. The operators most prevalent in terms of sociometric status are highlighted in black. This is OOW, SOC and OPSO who all undertake higher command based duties with the network diagrams revealing how central these operators are in terms of connecting the social network
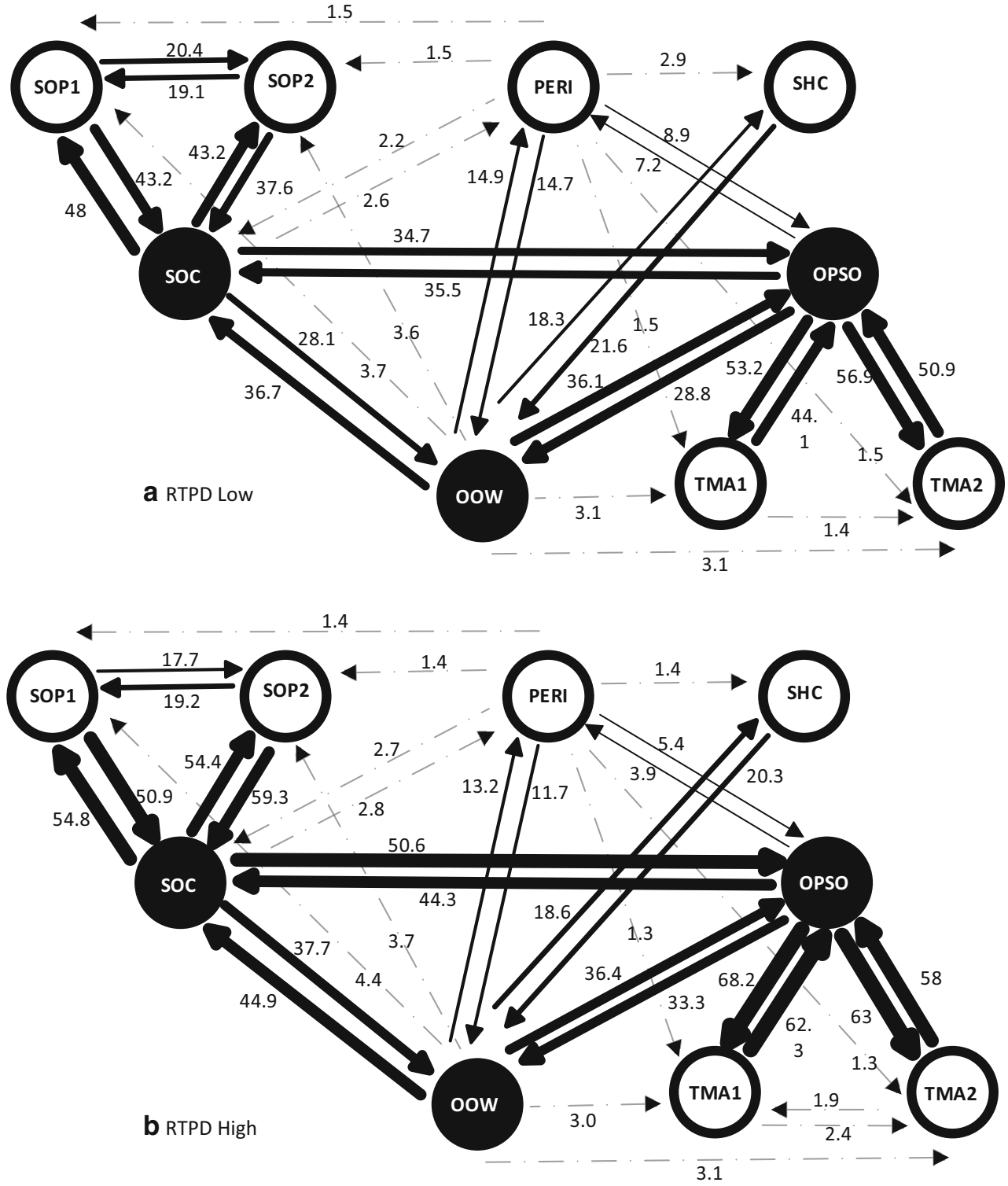

\subsection{Demand}

When examining the effect of scenario demand, post hoc analysis revealed the emissions, receptions and sociometric status of OPSO, SOC, TMA1 were statistically significantly higher $(p<.05)$ in the high-demand RTPD condition than in the low-demand condition (see Table 7 and Fig. 2). Indicating that these operators communicated more frequently and received more communications in the highdemand scenarios. Moreover, the higher sociometric status indicated that the importance of these operators increased during the high-demand scenarios. SOP2 had statistically significantly $(p<.05)$ higher receptions in the high-demand condition but not emissions. Indicating this operator received more communications but did not communicate more themselves. The eccentricity of PERI and TMA2 was statistically significantly $(p<.05)$ lower in the high-demand condition indicating these operators were less connected to the rest of the command team during the highdemand scenarios.

\subsection{Role}

When examining the effect of operator role post hoc analysis revealed that OPSO and SOC had statistically significantly $(p<.05)$ more emissions, receptions and higher sociometric status than all operators. These operators were required to communicate and receive more communications than any other command team members, making them the most important operators in the network. OOW had statistically significantly $(p<.05)$ more emissions than all operators (except OPSO and SOC). The 
Table 6 Social network metrics for global network

\begin{tabular}{llll}
\hline & \multicolumn{2}{l}{ RTPD } & Effect of demand $(t$ value $)$ \\
\cline { 2 - 3 } & Low & High & \\
\hline Nodes & 9 & 9 & NA \\
Edges & $36.80 \pm 3.01$ & $36.50 \pm 4.93$ & $t_{9}=.16, p=.88, \mathrm{NS}$ \\
Density & $0.51 \pm 0.04$ & $0.51 \pm 0.07$ & $t_{9}=.08, p=.94, \mathrm{NS}$ \\
Cohesion & $0.34 \pm 0.03$ & $0.35 \pm 0.03$ & $t_{9}=1.36, p=.21, \mathrm{NS}$ \\
Diameter & $3 \pm 0.00$ & $2.8 \pm 0.42$ & $t_{9}=1.5, p=.15, \mathrm{NS}$ \\
Total interactions & $663.80 \pm 206.32$ & $816.10 \pm 221.10$ & $t_{9}=2.12, p=.06, \mathrm{NS}$ \\
\hline
\end{tabular}

OOW was required to communicate more than most members of the command team but did not necessarily receive more communications than most other members. However, OOW, SOP1 and SOP2 had statistically significantly $(p<.05)$ more receptions than SHC and PERI, indicating the SOPs were required to receive a high number of communications compared to other members of the command team. Their importance in the network is also observable by the fact that OOW had statistically significantly $(p<.05)$ higher sociometric status than TMA1, TMA2, PERI and SHC but not higher than SOP1 and SOP2.

OOW and SOC had statistically significantly higher $(p<.05)$ centrality and closeness than all operators. Indicating OWO and SOC were central to the exchange of information between the entire command team and were communicating more directly with more members of the command team. OPSO had statistically significantly higher $(p<.05)$ centrality than all operators (except OOW and SOC). PERI had statistically significantly $(p<.05)$ higher centrality than SOP1, SOP2, TMA1, TMA2 and SHC, indicating that the information PERI shared was also central to the command team. OPSO and PERI had statistically significantly $(p<.05)$ higher closeness than SOP1, SOP2, TMA1, TMA2 and SHC. TMA1 and TMA2 had statistically significantly $(p<.05)$ greater farness and higher eccentricity than all operators. Indicating that these operators were less connected to the rest of the command team and as a result information had to travel a greater distance across the command team when involving these operators. SOP1, SOP2 and SHC had statistically significantly $(p<.05)$ greater farness and higher eccentricity than all operators (except TMA1 and 2). OPSO has statistically significantly $(p<.05)$ greater farness than OOW and SOC. Indicating that out of the most important nodes in the network (revealed by sociometric status) information had to travel the greatest distance when involving OPSO. However, OPSO and SOC had statistically significantly $(p<.05)$ higher between than all other operators. OOW had statistically significantly $(p<.05)$ higher betweeness than all operators (except OPSO and SOC). Indicating that these operators (OOW, OPSO and SOC) were information brokers in the command team, with SOC and OPSO being particularly important for this.

\subsection{Interaction between demand and role}

When examining the interaction between demand and operator role for emissions, receptions, sociometric status and betweeness post hoc analysis broadly revealed similar effects to those observed when examining operator role. Notable exceptions were that SOC had statistically significantly $(p<.05)$ more emissions than OOW during the high-demand RTPD condition, but not during the low-demand condition. Indicating SOC was required to communicate more than OOW in the high-demand condition but not in the low-demand condition. OOW had statistically significantly higher $(p<.05)$ sociometric status than SOP1, SOP2, TMA1 and TMA2 in the RTPD low-demand condition but not during the high-demand condition. This indicates that the overall importance of OOW in the network was reduced in the high-demand condition. OPSO and SOC had statistically significantly $(p<.05)$ higher betweeness than OOW in the low-demand RTPD condition but not during the high-demand condition. Indicating that despite OOW having less overall importance as a node in the network (lower sociometric status), the OOW became more of an information broker between command team members.

\subsection{Information network analysis}

The structure of the information networks is relatively consistent in both high and low-demand RTPD scenarios with 'contact', 'bearing' and 'solution' the most connected information pieces (see Fig. 3). The volume of emissions from most information elements appeared to increase in the high-demand RTPD scenario although differences in relationships can be observed.

\subsection{Global information network metrics}

No statistically significant differences between the high and low-demand scenarios were observed for global 


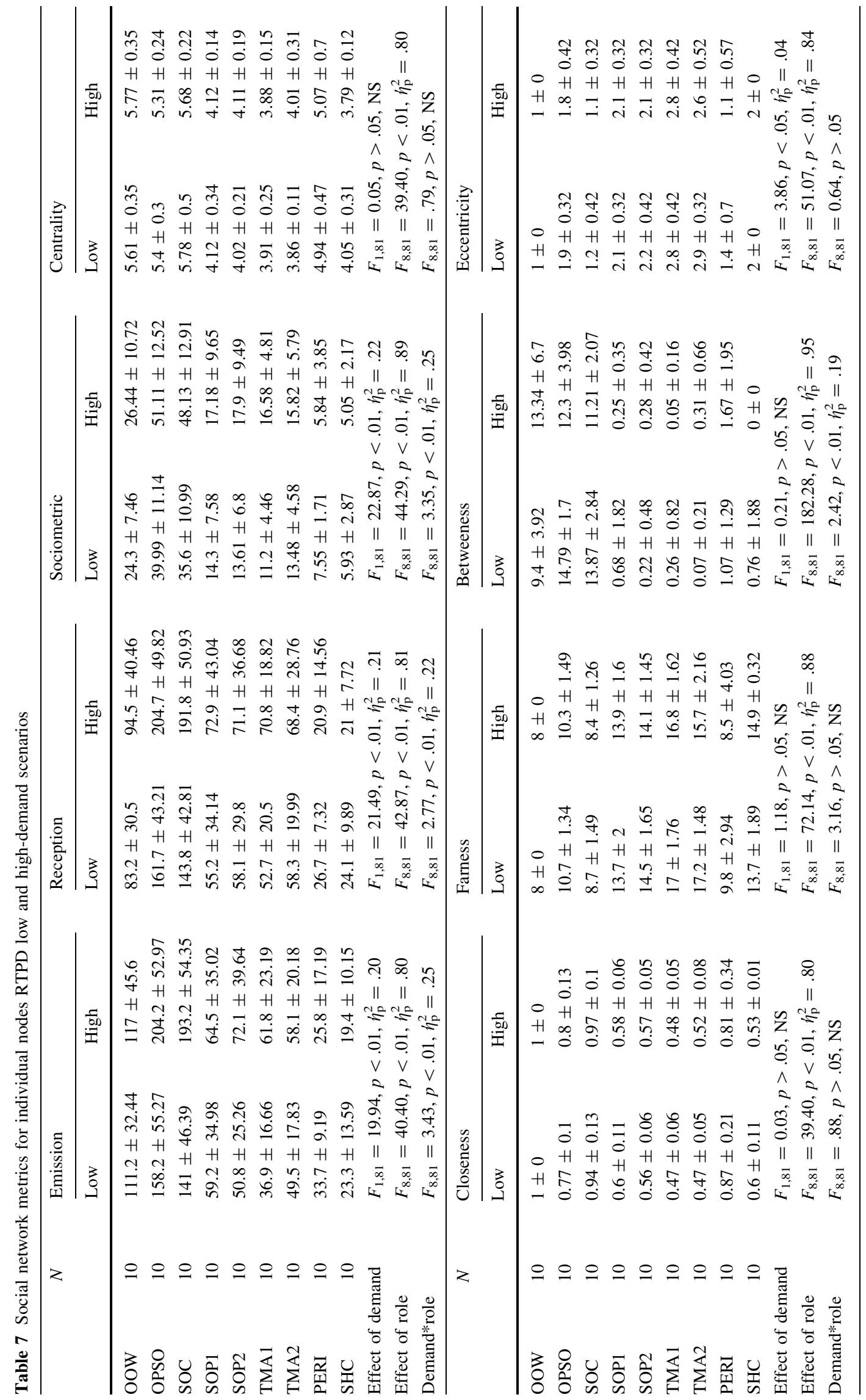



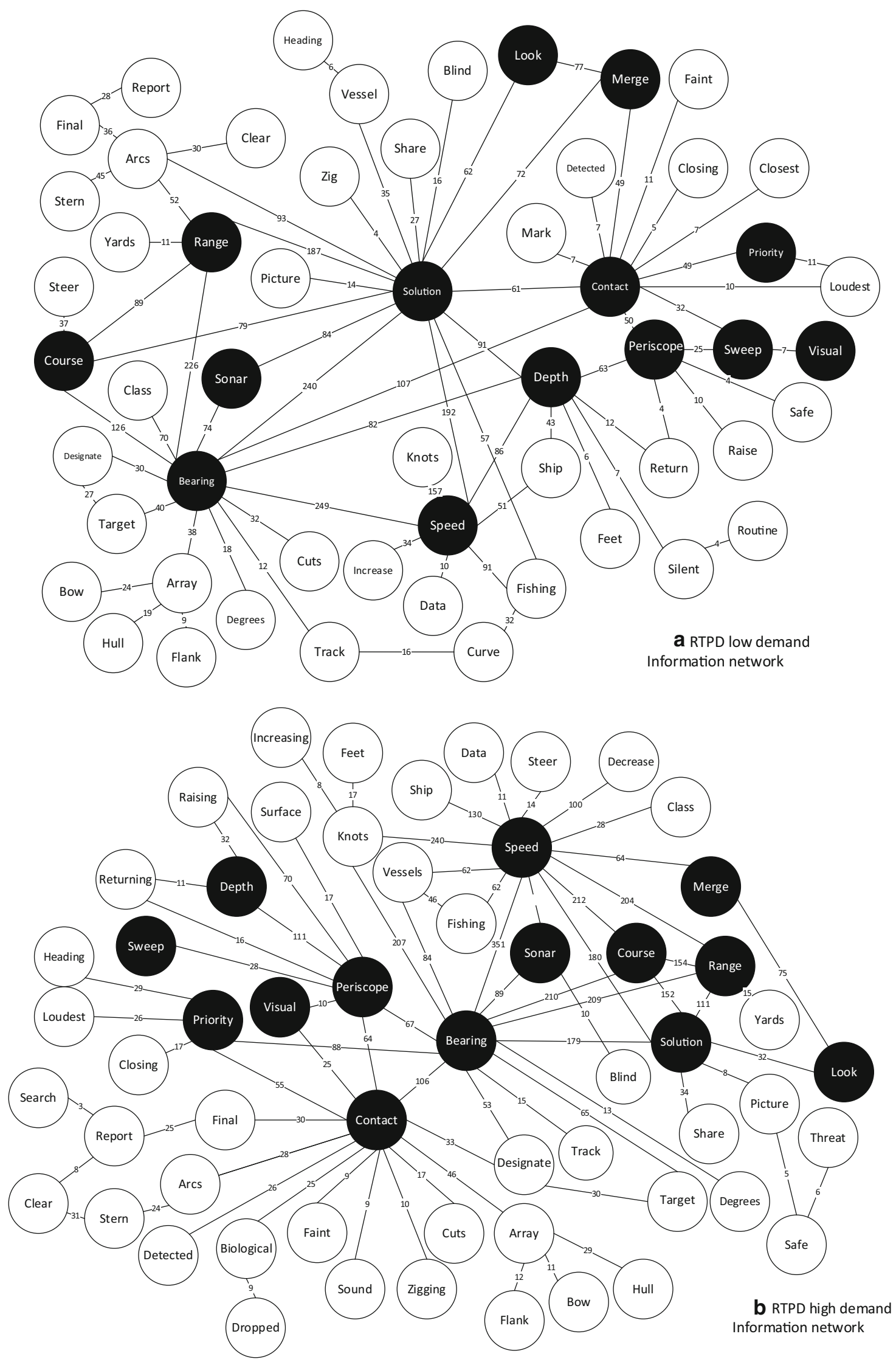
4Fig. 3 Information network diagrams for low and high-demand RTPD scenarios. This is a representation of key information nodes verbally communicated by members of the command team and the connectivity of all information. For purposes of clarity only connections with a frequency higher than 5 are represented. The highlighted nodes reveal the information with the greatest volume of emissions and receptions that were statistically analysed

network metrics (see Table 8), indicating that the overall structure of information used by operators did not vary as a result of scenario demand.

\subsection{Nodal information network metrics}

The main effects of demand, information type and interaction between demand and information type are presented in Table 9. Overall, emissions and receptions of nodes statistically significantly increased $(p<.05)$ in the highdemand RTPD scenarios compared to the low-demand RTPD scenarios. The post hoc statistical analysis of significant effects is described below.

\subsection{Demand}

The emissions and receptions of bearing, contact, priority, sonar, speed and range were statistically significantly $(p<.05)$ higher in the high-demand condition than in the low-demand condition. Indicating that this type of information was passed between command team members more frequently in the high-demand RTPD scenarios compared to the low-demand scenarios.

\subsection{Information type}

Post Hoc analysis also revealed emissions, receptions and sociometric status of bearing were statistically significantly higher $(p<.05)$ than look, merge, priority, sweep, sonar and visual (see Table 9 and Fig. 3). Emissions, receptions and sociometric status of course were statistically significantly higher $(p<.05)$ than priority, sweep and visual. Speed had statistically significantly $(p<.05)$ more emissions, receptions and higher sociometric status than merge, look, sweep, visual and priority. Solution had statistically significantly $(p<.05)$ more emissions, receptions and higher sociometric status than sweep and visual (see Table 9 and Fig. 3). The comparison of emissions and receptions of information facilitates an understanding of which information was exchanged more prevalently between members of the command team, whilst sociometric status reveals which information is the most important piece of information in the network. The results reveal that bearing is the most piece of information exchanged between command team members.

Post hoc analysis revealed that bearing had statistically significantly higher $(p<.05)$ centrality and closeness than merge, priority, sweep and visual. The centrality and closeness of course was statistically significantly higher $(p<.05)$ than sweep and visual. However, contact had statistically significantly higher $(p<.05)$ centrality and closeness than merge, priority, sonar, sweep, range and visual. Solution and speed had statistically significantly $(p<.05)$ higher centrality and closeness than sweep and visual. The comparison of the centrality and closeness of information reveals which information is central to the network and which information is most closely linked to all other pieces of information. Bearing is again the most central piece of information and is connected to the greatest volume of other information by the shortest pathways. Course and contact are similarly prevalent pieces of information in terms of centrality and closeness.

Bearing, course, periscope, solution, speed, depth and contact had statistically significantly $(p<.05)$ lower farness than visual. Contact had statistically significantly $(p<.05)$ lower farness than sweep. This indicates that information such as visual and sweep was the most disparate pieces of information in the network compared to all other information. Bearing had statistically significantly $(p<.05)$ higher betweeness than merge, priority, sonar, sweep, range and visual. Contact had statistically significantly higher $(p<.05)$ betweeness than all other information pieces except bearing. Solution and speed had statistically significantly statistically significantly $(p<.05)$ higher farness higher betweeness than sweep and visual. This indicates that information such as bearing, contact, solution and speed was persistently information brokers between more disparate pieces of information ibn terms of network connectivity.
Table 8 Information network metrics for global network

\begin{tabular}{lccl}
\hline Demand & Low & High & Effect of demand $(t$ Value $)$ \\
\hline Nodes & $45.60 \pm 5.10$ & $44.40 \pm 6.46$ & $t_{9}=.45, p=.66, \mathrm{NS}$ \\
Edges & $702.10 \pm 330.28$ & $644.80 \pm 357.54$ & $t_{9}=.60, p=.56, \mathrm{NS}$ \\
Density & $0.49 \pm 0.15$ & $0.49 \pm 0.19$ & $t_{9}=.09, p=.93, \mathrm{NS}$ \\
Cohesion & $0.37 \pm 0.13$ & $0.35 \pm 0.10$ & $t_{9}=.81, p=.44, \mathrm{NS}$ \\
Diameter & $3.30 \pm 0.82$ & $3.5 \pm 0.53$ & $t_{9}=1.0, p=.34, \mathrm{NS}$ \\
Total emissions & $2412.10 \pm 1424.21$ & $2898.90 \pm 2620.68$ & $t_{9}=.85, p=.42, \mathrm{NS}$ \\
\hline
\end{tabular}




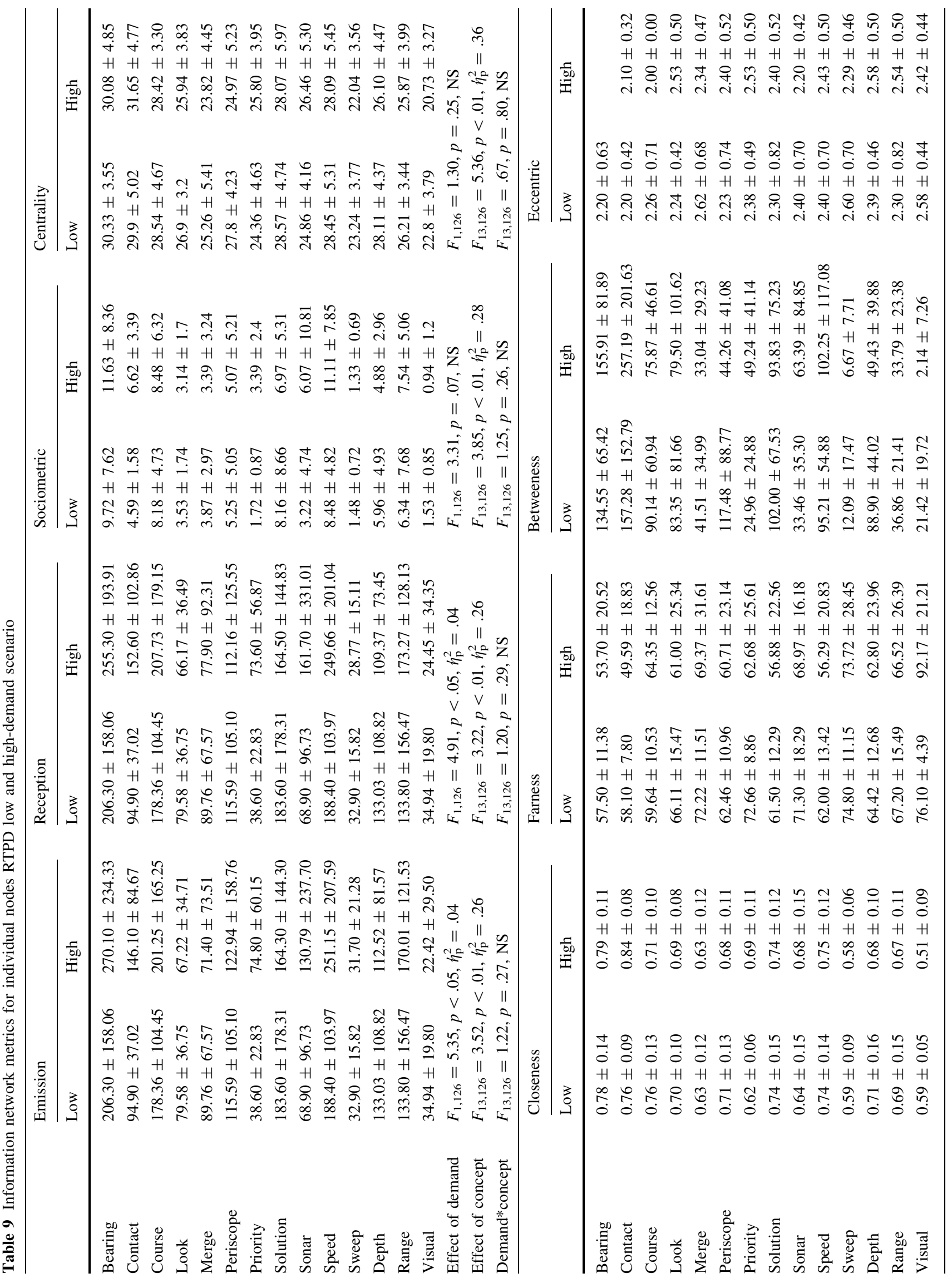


Bearing had statistically significantly $(p<.05)$ higher betweeness than priority, sweep and visual in the low-demand condition but only with sweep and visual in the highdemand condition. Contact had statistically significantly $(p<.05)$ higher betweeness than merge, priority, sonar, sweep, range and visual in the low-demand condition but only with depth and visual in the high-demand condition. This indicates the role of information such as bearing and contact in connecting disparate pieces of information was reduced in the high-demand condition.

\subsection{Task network analysis}

The type of tasks completed by the command team was the same for high and low-demand scenarios and so one network diagram detailing the task network is presented (see Fig. 4). The network metrics (node and global) have been calculated for a single network and are presented (see Tables 10 and 11). However, the frequency of task completion varied based upon demand; the results of this analysis are presented in Table 12. The subtasks presented in the network diagram centre around the generation of a tactical picture. The completion of numerous subtasks (e.g. detecting contacts, designating contacts, then estimating contact speed) helps build a sonar picture to promote awareness of surrounding contacts, before a submarine is permitted to RTPD (see Fig. 4).

\subsection{Global task network metrics}

As the task network was identical for both low and highdemand scenarios, no comparison has been made (see Table 10), rather the global network metrics are reported for the overall network.

\subsection{Nodal task network metrics}

The metrics for the individual nodes in the network are shown in Table 11. The task with the highest number of emissions was 'building the sonar picture' which required the completion of numerous subtasks (i.e. data analysis and assimilation) to inform the generation of the overall tactical picture when operating at depth (see Table 11). The verification of tasks networks by SMEs provided the basis for the completion of task frequency analysis.

\subsection{Task frequency analysis}

Post hoc analysis revealed that overall the frequency of task completion was statistically significantly higher 


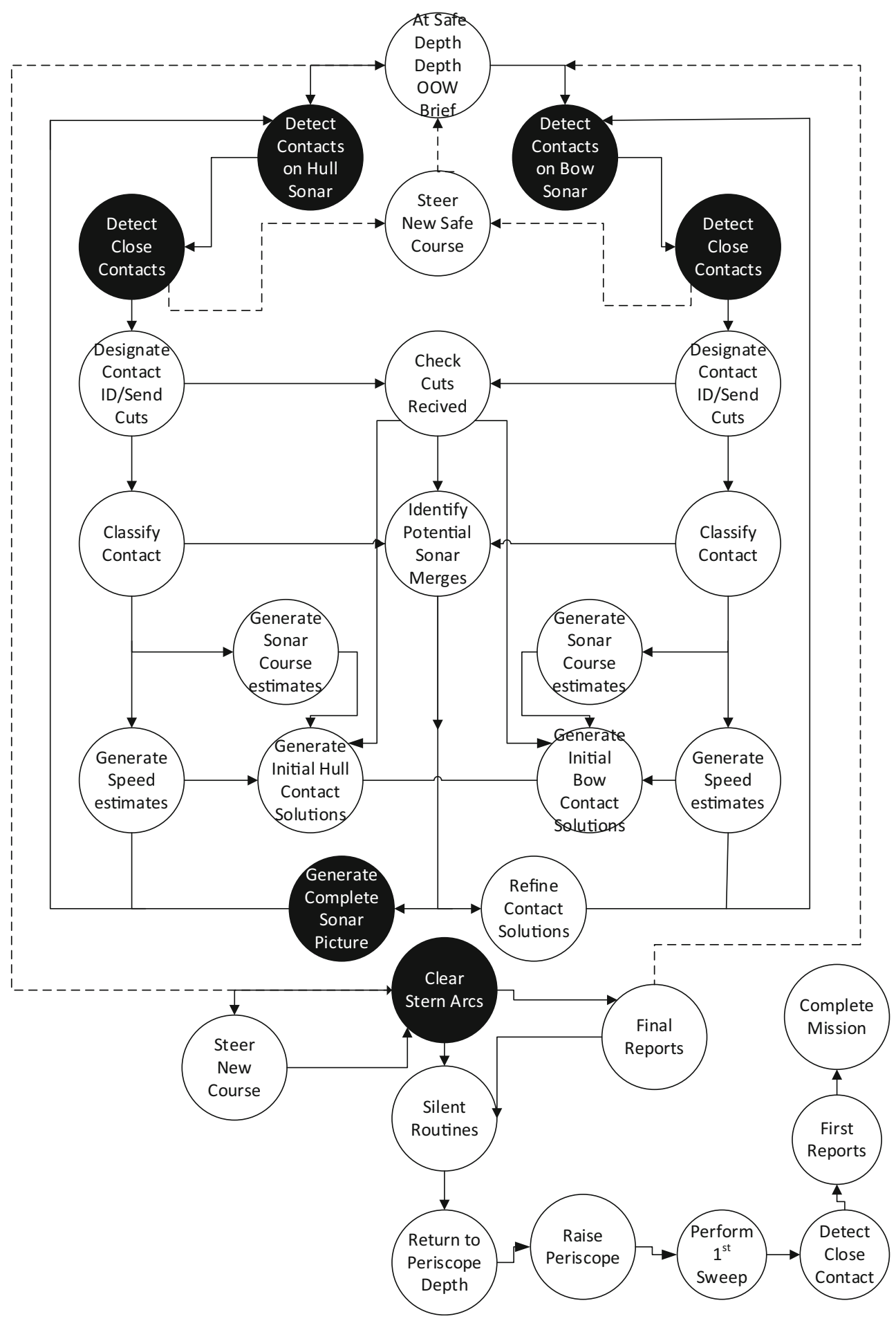

Fig. 4 Task network diagrams for RTPD low and high-demand scenarios. The task nodes reveal what type of task needs to be completed and how each task is connected to additional tasks. Dotted lines represent a connection between tasks that only exists in particular circumstances. For example, clearing stern arcs

$(p<.05)$ in the high-demand condition than in the lowdemand condition. This indicates that the command team had more to do during the high-demand condition. Further (completing a turn to monitor sonar blind spot) only leads to a new OOW brief if a new contact is found to the stern of the submarine that was not previously detected. The task nodes with the highest sociometric status have been highlighted

analysis revealed the tasks of detecting, classifying, generating solutions, refining solutions and generating speed estimates from sonar were statistically significantly 
Table 10 Task network metrics for global network

\begin{tabular}{ll}
\hline Metric & Value \\
\hline Nodes & 27 \\
Edges & 46 \\
Density & 0.06 \\
Cohesion & 0.01 \\
Diameter & 12 \\
Total interactions & 92 \\
\hline
\end{tabular}

$(p<.05)$ higher than all other tasks (see Table 12). This indicates that there was more of these tasks to be completed at that the command team completed more of these tasks to facilitate the global objective of returning to periscope depth. Changes to own submarine parameters were completed statistically significantly $(p<.05)$ more than all tasks relating to periscope (e.g. raising periscope and detecting visual contacts). The frequency of task completion for detection, designation and classification of sonar contacts was statistically significantly $(p<.05)$ higher than sweep periscope and detect visual and designate visual in the high-demand RTPD condition but not in the low-demand condition (see Table 12).

\section{Discussion}

The social, information and task networks presented in this paper provide a detailed description of the interactions that occur within a simulated submarine control room (Loft et al. 2013; Stanton and Bessell 2014; Huf et al. 2004). The current work was validated whilst offering support for previous work which examined an operational Royal Navy team in a high-fidelity training simulator during a return to periscope depth, although demand was not manipulated in this study (Stanton 2014). In particular, OOW and OPSO have the highest sociometric status highlighting the importance of these operators (Stanton 2014). The type of information that was exchanged with the greatest frequency was also similar; typically 'contact' was a critical

Table 11 Task network metrics for individual nodes RTPD scenarios

\begin{tabular}{|c|c|c|c|c|c|c|c|c|}
\hline & Emission & Reception & Sociometric & Centrality & Closeness & Farness & Betweeness & Eccentricity \\
\hline OOW brief & 1 & 4 & 0.19 & 11.18 & 0.16 & 159 & 40.00 & 12 \\
\hline Detect contacts sonar & 3 & 2 & 0.19 & 12.59 & 0.19 & 134 & 69.23 & 11 \\
\hline Close sonar contact & 3 & 2 & 0.19 & 14.04 & 0.22 & 120 & 73.71 & 10 \\
\hline Designate sonar contact & 2 & 2 & 0.15 & 11.35 & 0.17 & 153 & 77.00 & 12 \\
\hline Classify sonar contacts & 3 & 1 & 0.15 & 11.72 & 0.19 & 137 & 41.04 & 11 \\
\hline Speed estimates & 1 & 3 & 0.15 & 11.07 & 0.17 & 157 & 3.50 & 11 \\
\hline Sonar courses & 1 & 1 & 0.08 & 10.29 & 0.17 & 154 & 0.50 & 11 \\
\hline Identify sonar merges & 2 & 2 & 0.15 & 12.24 & 0.21 & 124 & 68.35 & 10 \\
\hline Check cuts are received & 2 & 1 & 0.12 & 11.35 & 0.18 & 143 & 33.96 & 11 \\
\hline Build sonar picture & 4 & 1 & 0.19 & 12.96 & 0.25 & 104 & 36.45 & 9 \\
\hline Generate solutions & 1 & 3 & 0.15 & 12.66 & 0.20 & 133 & 63.65 & 10 \\
\hline Steer safe course & 2 & 2 & 0.15 & 13.04 & 0.21 & 126 & 49.00 & 9 \\
\hline Refine solutions & 3 & 3 & 0.23 & 14.14 & 0.24 & 109 & 121.05 & 9 \\
\hline Clear stern arcs & 2 & 3 & 0.19 & 13.52 & 0.21 & 125 & 174.56 & 8 \\
\hline Final reports & 3 & 1 & 0.15 & 14.23 & 0.24 & 108 & 174.00 & 7 \\
\hline Silent routines & 1 & 1 & 0.08 & 22.13 & 0.68 & 38 & 75.00 & 6 \\
\hline Normal routines & 1 & 1 & 0.08 & 22.13 & 0.68 & 38 & 75.00 & 6 \\
\hline RTPD & 1 & 2 & 0.12 & 20.67 & 0.93 & 28 & 153.00 & 5 \\
\hline Raise periscope & 2 & 2 & 0.15 & 18.11 & 1.37 & 19 & 158.00 & 4 \\
\hline 1st sweep & 1 & 1 & 0.08 & 16.85 & 4.33 & 6 & 54.00 & 3 \\
\hline Detect close visual & 1 & 1 & 0.08 & 14.61 & 8.67 & 3 & 34.00 & 2 \\
\hline First reports & 1 & 1 & 0.08 & 12.74 & 26.00 & 1 & 12.00 & 1 \\
\hline ESM check & 1 & 1 & 0.08 & 15.01 & 1.00 & 26 & 69.00 & 6 \\
\hline Confirm submarine safe & 2 & 1 & 0.12 & 13.78 & 1.24 & 21 & 56.00 & 5 \\
\hline Raise WT mast & 1 & 1 & 0.08 & 13.61 & 26.00 & 1 & 12.00 & 1 \\
\hline Lower periscope & 1 & 1 & 0.08 & 12.17 & 1.08 & 24 & 9.00 & 5 \\
\hline Complete mission & 0 & 2 & 0.08 & 11.59 & 0.00 & 0 & 0.00 & 0 \\
\hline
\end{tabular}


Table 12 Frequency of task completion RTPD scenarios

\begin{tabular}{|c|c|c|}
\hline \multicolumn{3}{|l|}{ RTPD } \\
\hline Demand & Low & High \\
\hline Detect sonar contacts & $4 \pm 1.89$ & $8.7 \pm 4.22$ \\
\hline Designate sonar contacts & $3.3 \pm 1.64$ & $7.7 \pm 4.85$ \\
\hline Classify sonar contacts & $3.8 \pm 1.87$ & $10.5 \pm 4.3$ \\
\hline Sonar speed estimates & $5.4 \pm 2.27$ & $10.9 \pm 5.67$ \\
\hline Sonar course estimates & $1.2 \pm 1.23$ & $4.9 \pm 2.13$ \\
\hline Check cuts & $2.4 \pm 1.84$ & $3.9 \pm 1.52$ \\
\hline Sonar merges & $3.4 \pm 1.35$ & $2.8 \pm 1.81$ \\
\hline Sonar solution & $4.6 \pm 1.96$ & $10.7 \pm 3.53$ \\
\hline Refine solutions & $4.2 \pm 3.58$ & $5.1 \pm 3.63$ \\
\hline Change submarine parameters & $4.4 \pm 2.46$ & $4.3 \pm 2.06$ \\
\hline Raise periscope & $1 \pm 0$ & $0.8 \pm 0.42$ \\
\hline Complete sweep & $1.8 \pm 0.63$ & $0.8 \pm 0.42$ \\
\hline Detect visual contacts & $1.7 \pm 0.95$ & $1.4 \pm 1.07$ \\
\hline Designate visual contacts & $1.3 \pm 1.06$ & $1.1 \pm 1.1$ \\
\hline Classify visual contacts & $0.7 \pm 0.82$ & $1.1 \pm 2.02$ \\
\hline Range visual contacts & $0.8 \pm 1.03$ & $1.6 \pm 2.5$ \\
\hline Course estimates of visual & $0.4 \pm 0.97$ & $1 \pm 2.83$ \\
\hline Visual solutions & $0.1 \pm 0.32$ & $0.1 \pm 0.32$ \\
\hline Merge visual and sonar & $0.7 \pm 0.82$ & $0.3 \pm 0.95$ \\
\hline Clear stern arcs & $1 \pm 0$ & $1 \pm 0.47$ \\
\hline Final reports & $1 \pm 0$ & $0.9 \pm 0.32$ \\
\hline Effect of demand & $F_{1,189}=57$ & $<.01, \eta_{\mathrm{p}}^{2}=.23$ \\
\hline Effect of task type & $F_{20,189}=25$ & $p<.01, \eta_{\mathrm{p}}^{2}=.73$ \\
\hline Demand*task & $F_{20,189}=7$. & $<.01, \eta_{\mathrm{p}}^{2}=.90$ \\
\hline
\end{tabular}

piece of information, in relation to information such as bearing, course and range (Stanton 2014).

\subsection{Demand}

The general structure of the social, information and task networks did not vary between the high and low-demand conditions, suggesting that current control room configurations have flexibility in the system to adapt to different levels of demand. However, the number of interactions (emissions and reception) between operators increased as did the volume and complexity of contacts. This suggests that a submarine control room adapts to increased demand by communicating more frequently to pass greater volumes of information. If increased demand (e.g. a greater number of contacts) inflates the number of information exchanges and volume of information being passed by the command team in a linear fashion, this may have a negative impact upon performance (Stanton 2011; Stanton et al. 2015a, b; Salas et al. 2001; Carletta et al. 2000). In particular the emissions of OPSO and SOC drastically increased in the high-demand to the point where their emissions and receptions were nearly double that of all other members of the command team. It seems that other media to support command team communication and sharing of information need to be explored to prevent command team members such as OPSO being overloaded (Stanton et al. 2002). This view is supported by the fact that in the high-demand scenarios the command team appeared to adapt to higher demand by task shedding tasks such as 'completing sonar merges' and 'periscope sweeps' with both tasks being facilitated by SOC and OPSO, respectively.

The heightened eccentricity of PERI and TMA2 in the high-demand condition indicates that during situations of increased demand members of the command team can become disconnected from the overall social network. A sociotechnical system requires effective interaction between humans and technology, but also from humanhuman (Walker et al. 2008, 2009). These operators are becoming potentially more distant from the command team due to communication technologies (e.g. radio network) and interface designs placing physical limitations on the passage of critical information (e.g. if one operator is monopolising the network). This is likely to negatively impact upon overall sociotechnical system performance, particularly if these operators hold information from a particular sensor that the command team may benefit from being shared. This offers support for previous work stating that technological advancements (i.e. improved sensor capabilities) do not necessarily optimise performance if they are not effectively integrated (Dominguez et al. 2006).

\subsection{Social network analysis}

PERI and SHC had significantly lower sociometric status than all other operators. This offers support for previous work showing that during a return to periscope depth passive sonar is the primary sensor used (Shar and Li 2000; Stanton 2014). This is further validated by the fact that SOP1 and SOP2 had a greater number of emissions and greater sociometric status than all operators in the command team (except SOC, OPSO and OOW). This suggests that the information being generated by SOPs is critical to the generation of a tactical picture and safe operation (Jones et al. 2011). SOC has the highest centrality and closeness of all operators in the command team (except OOW). SOC is responsible for distributing sonar information to relevant members of the command team. The high centrality of SOC further demonstrates the criticality of sonar information but potentially highlights the ambiguity of sonar data as a primary role of SOC is to quality check such information (Zarnich 1999; Ogden et al. 2011).

OOW, SOC and OPSO represent 'higher command' in the submarine control room and have the largest number of interactions (emissions and receptions). Interestingly, 
OOW has lower sociometric status than OPSO and SOC highlighting that despite making key tactical decisions, the $\mathrm{CO}$ is not the busiest person in the control room (Dominguez et al. 2006; Mansell et al. 2003; Chalmers 2010). Despite this, the OOW has the highest centrality of all operators in the command team showing that the OOW is the team fulcrum. The high sociometric status and betweeness of SOC and OPSO demonstrate the importance of these operators in terms of tactical picture generation (Stanton 2011; Salas et al. 2001; Carletta et al. 2000). The low betweeness values of the SOP and TMA operators further demonstrate that these operators are at the edge of the team. This represents a potential 'bottleneck' in the system, with a reliance on OPSO and SOC to mediate between operators at the edge of the team. This demonstrates how team configuration can impact on its functioning (Stanton, Rothrock, Harvey \& Sorensen, a, b). Examining rooms from a sociotechnical perspective can provide knowledge of optimal configurations and structure based upon which operators communicate most frequently (Walker et al. 2008, 2009). It also facilities understanding of how information should be presented and how interfaces should be designed based upon the connectivity of information and tasks.

\subsection{Information network analysis}

The information with the highest number of emissions and greatest sociometric status was 'bearing'. The ambiguity associated with the primary sensor (passive sonar) being used during a return to periscope depth means the only definite information a command team has concerning surrounding vessels is bearing (Shar and Li 2000; Stanton 2014; Zarnich 1999; Ogden et al. 2011). However, the information with the greatest betweeness was 'contact'. A primary objective of submarine operations is to maximise safety, particularly in relation to other 'contacts' sharing the ocean (Jones et al. 2011). 'Speed', 'course' and 'solution' have similarly high sociometric status to each other in both low and high-demand conditions. It is the generation of 'contact' 'solutions' that facilitate the generation of a tactical picture. Along with 'bearing' information estimates of 'speed' and 'course' from sonar are what TMAs use to generate solutions. Estimates of 'speed' are more reliable and more quickly acquired by SOPs than 'course' demonstrating why the betweeness of speed increases in the high-demand condition, whereas the betweeness of 'course' decreases as operators have less time to dedicate to more difficulty to acquire and/or ambiguous information sources. The high value and connectivity of information such as 'bearing', 'speed' and 'course' to inform 'solution' generation is supported by prior work (Stanton et al. 2006; Stanton 2014; Stanton and Bessell 2014).
The lowest value number of emissions and receptions was observed for 'visual' information; this supports what was observed in the social network analysis as when operating at depth that 'sonar' information is relied upon (Shar and Li 2000; Stanton 2014). 'Priority' had a low volume of emission and sociometric status in the low-demand condition, but this more than doubled during the high-demand condition. This suggests that to cope with increased demand (e.g. volume of contacts to be tracked) more emphasis was placed on identifying 'priority' contacts that were deemed to be potentially more hazardous during a return to periscope depth (Hunter et al. 2014; Loft et al. 2013).

\subsection{Task network analysis}

The tasks most frequently completed by the command team are related to sonar (detection, designation, speed estimates and solution generation). This provides further support to the fact that sonar is the primary senor used when operating at depth (Shar and Li 2000; Stanton 2014). The frequency of task completion for classification, speed estimate generation and solution generation increased the most out of all tasks in the high-demand condition. The classification of a vessel allows a command team to prioritise contacts based upon the likely threat posed to the submarine and so may help to reduce workload (e.g. promote a focus on accurate solution generation for priority contacts in terms of threat). A transition from deep to shallow waters is arguably the most dangerous of the routine operations completed by submarines, understanding what type of vessels surround the submarine (e.g. fishing vessels with trawl nets) appears to be a key task to cope with increased workload in complex waters (Drumheller and Benoit 2004).

The tasks related to changing own submarine parameters remains consistently high across the high and low conditions. Submarines change course to enable the ranging of contacts (e.g. using triangulation techniques); speed changes are required so that it is safe to raise periscope without damage and depth changes are made to complete a return to periscope depth. Manoeuvring to a safe location to return to periscope depth based upon the tactical picture generated is a key aspect of safe submarine operation for a variety of mission objectives (Bateman 2011; Stanton 2014). The completion of tasks related to visual information (e.g. raise periscope and search for visual contacts) is completed the least. Once a return to periscope depth is complete, periscope might only be used to provide visual confirmation that the submarine is safe and briefly confirm the tactical picture (e.g. confirm range of priority contacts), periscope may only be raised for a short time as a primary objective of submarines is to remain covert (Bateman 2011; Stanton 2014). 


\subsection{Limitations and future research}

A limitation of the current work is that the cohort recruited were primarily novices with short training histories (relatively speaking), which limits the overall generalisability of the results. It is likely that the results will not have absolute validity (e.g. be numerically comparable to expert teams) but will have relative validity (e.g. direction of effects) due to the submarine simulator and the entire study design (e.g. training materials, tasks and scenarios) being validated by SMEs and one of the teams tested being operational submariners. The use of novices for command and control studies has been shown to be effective in previous research (Walker et al. 2010). Moreover, the results were comparable to a Royal Navy team completing training in a high-fidelity simulator for a similar scenario (e.g. sociometric status of OOW) even though the operational parameters were not identical (Stanton 2014). However, future research should aim to statistically compare navy teams to non-navy teams to ascertain the validity of the work, facilitating an understanding of which aspects can directly inform control room design (Stanton et al. 2010) and which aspects require higher-fidelity testing. Future research should also examine whether a change in command structure and control room layout may facilitate direct communication between operators who are routinely sharing information via OPSO (e.g. SOPs and TMAs).

\section{Conclusions}

The current work has provided empirical evidence for clear delineations between submarine command team operators in terms of social, information and task network analysis. During a return to periscope depth, sonar information is critical, reflected by the communications between operators in the command team, type of information passed and the frequency of tasks completed. This information can be used to inform the design of future submarine control rooms but also provide insight into the design of control rooms in general that are applicable to many other domains such as air traffic control and energy power plants (Stanton et al. 2010). The current work indicates a potential for streamlining the transition of sonar information to solution generation, potentially by merging the SOP and TMA roles, or at least assessing their capacity to communicate more directly (e.g. not solely via OPSO and SOC). This highlights a high reliance on the communication between OPSO and SOC, with these operators being integral to command team performance. In the current control room configuration, these operators are positioned in separate rooms, so future work could examine if proximity-based control room configurations might reduce the communicative load placed on OPSO and SOC (Stanton et al. 2002, 2003).

Interface redesign might also reduce the amount of verbal communications when resolving ambiguous information. During the high-demand scenarios the focus of information appeared to shift away from the use of ambiguous information (e.g. sonar course generation) to more certain information (e.g. sonar speeds) and the prioritisation of contacts (e.g. classifications). This finding could be used to inform the design of future technologies that adapt to the demand placed on a command team. The current work provides a greater understanding of the functioning of contemporary submarine control rooms during a return to periscope depth scenario. It provides a baseline from which to compare future configurations and ways of working. Finally, it is worth noting that the studies were undertaken using a submarine simulation that allows some control over the scenario, activity setting and observation. Whilst the various network patterns described are likely to be a reasonable facsimile of operations at sea, validating those patterns at sea would be beneficial. Nevertheless, the study does provide greater insights in some of the nuances of command and control teams (Stanton et al. 2008). This is likely to be generalisable beyond submarines to other command and control (Stanton et al. 2015a, b; Houghton et al. 2006) and control room (Stanton et al. 2003, 2010) domains.

Acknowledgements This work was supported in part by the Human Sciences Domain of the UK Ministry of Defence Scientific Research Programme, contract TIN3.113. Any views expressed are those of the authors and do not necessarily represent those of the Ministry of Defence or any other UK government department.

Open Access This article is distributed under the terms of the Creative Commons Attribution 4.0 International License (http://crea tivecommons.org/licenses/by/4.0/), which permits unrestricted use, distribution, and reproduction in any medium, provided you give appropriate credit to the original author(s) and the source, provide a link to the Creative Commons license, and indicate if changes were made.

\section{References}

Bateman S (2011) Perils of the deep: the dangers of submarine proliferation in the seas of east Asia. Asian Secur 7(1):61-84

Carletta J, Anderson AH, McEwan R (2000) The effects of multimedia communication technology on non-collocated teams: a case study. Ergonomics 43:1237-1251

Chalmers B 2010 A work-centred approach to optimizing humansystem integration in command and control for the victoria class submarine, Proceedings of undersea human systems integration symposium, American society of naval engineers, $\mathrm{p}$ 10-14

Dominguez C, Long WG, Miller TE, Wiggins SL 2006 Design directions for support of submarine commanding officer decision making. In: Proceedings of 2006 undersea HSI symposium: research, acquisition and the warrior, Mystic, 6-8 June 2006, p 6-8 
Drumheller K, Benoit WL (2004) USS Greeneville collides with Japan's Ehime Maru: cultural issues in image repair discourse. Public Relat Rev 30(2):177-185

Duryea DM, Lindstrom CE, Sayegh R 2008 Submarine imaging systems: developing improved capabilities and technologies. In: SPIE defence and security symposium proceedings. April 2006, Florida, p. 69430X-69430X

Espevik R, Johnsen BH, Eid J, Thayer JF (2006) Shared mental models and operational effectiveness: effects on performance and team processes in submarine attack teams. Mil Psychol 18(S):S23

Houghton RJ, Baber C, McMaster R, Stanton NA, Salmon P, Stewart $\mathrm{R}$, Walker G (2006) Command and control in emergency services operations: a social network analysis. Ergonomics 49(12-13):1204-1225

Huf S, French HT 2004 Situation awareness in a networked virtual submarine. In: proceedings of the human factors and ergonomics society annual meeting vol 48, no 3 Sage Publications, Denver, p 663-667

Hunter A, Hazen M, Randall T (2014) Victoria class submarine human-in-the-loop experimentation plan. Defence Research and Development, Atlantic, Dartmouth

Jones E, Steed R, Diedrich F, Armbruster R, Jackson C (2011) Performance-based metrics for evaluating submarine command team decision-making. In: Schmorrow DD, Fidopiastis CM (eds) Foundations of augmented cognition. Directing the future of adaptive systems. Springer, Berlin Heidelberg, pp 308-317

Lee JD, Kantowitz BH (2005) Network analysis of information flows to integrate in-vehicle information systems. Int $\mathrm{J}$ Veh Inf Commun Syst 1(1-2):24-43

Loft S, Morrell DB, Huf S (2013) Using the situation present assessment method to measure situation awareness in simulated submarine track management. Int $\mathrm{J}$ Hum Factors Ergon 2(1):33-48

Mansell T, Tynan A, Kershaw D 2003 Investigating the network enabled conventional submarine: an Australian perspective. Undersea defence technology (UDT), Pacific. Downloaded from department of defence command and control research portal http://dodccrp.org/events/2002_CCRTS/Tracks/pdf/106.PDF

Ogden GL, Zurk LM, Jones ME, Peterson ME (2011) Extraction of small boat harmonic signatures from passive sonar. J Acoust Soc Am 129(6):3768-3776

Read GJ, Salmon PM, Lenne MG, Stanton NA (2015) Designing sociotechnical systems with cognitive work analysis: putting theory back into practice. Ergonomics 58(5):822-851

Roberts A, Stanton NA, Fay D 2015 The command team experimental test-bed stage 1: design and build of a submarine command room simulator. In: proceedings of international conference on applied human factors and ergonomics (AHFE), procedia manufacturing, 3, p 2800-2807

Salas E, Burke CS, Samman SN (2001) Understanding command and control teams operating in complex environments. Inf Knowl Syst Manag 2:311-323

Shar P, Li XR (2000) Passive sonar fusion for submarine C2 systems. IEEE Aerosp Electron Syst Mag 15(3):29-34

Shattuck LG, Miller NL (2006) Extending naturalistic decision making to complex organizations: a dynamic model of situated cognition. Organ Stud 27(7):989-1009

Stanton NA (2011) Trust in military teams. Ashgate, Aldershot

Stanton NA (2014) Representing distributed cognition in complex systems: how a submarine returns to periscope depth. Ergonomics 57(3):403-418

Stanton NA (2016) Distributed Situation Awareness. Theor issues Ergon Sci 17(1):1-7
Stanton NA, Bessell K (2014) How a submarine returns to periscope depth: analysing complex sociotechnical systems using cognitive work analysis. Appl ergon 45(1):110-125

Stanton NA, Harvey C (2016) Beyond human error taxonomies in assessment of risk in sociotechnical systems: a new paradigm with the EAST 'broken-links' approach. Ergonomics 60(2):221-233

Stanton NA, Connelly V, Prichard J, Van Vugt M (2002) Assessing the effects of location, media and task type on team performance. J Def Stud 7(1):29-41

Stanton NA, Ashleigh M, Roberts A, Xu F (2003) Virtuality in human supervisory control: assessing the effects of psychological and social remoteness. Ergonomics 46(12):1215-1232

Stanton NA, Stewart R, Harris D, Houghton RJ, Baber C, Mcmaster R, Salmon P, Hoyle G,Walker G, Young MS, Linsell M (2006) Distributed situation awareness in dynamic systems: theoretical development and application of an ergonomics methodology. Ergonomics 49(12-13):1288-1311

Stanton NA, Baber C, Harris D (2008a) Modelling command and control: event analysis of systemic teamwork. Ashgate, Aldershot

Stanton NA, Baber C, Walker GH, Houghton RJ, McMaster R, Stewart R, Harris D, Jenkins DP, Young MS, Salmon PM (2008b) Development of a generic activities model of command and control. Cogn Technol Work 10(3):209-220

Stanton NA, Salmon PM, Walker GH, Jenkins DP (2009) Genotype and phenotype schemata as models of situation awareness in dynamic command and control teams. Int $\mathrm{J}$ Ind Ergon 39(3):480-489

Stanton NA, Salmon PM, Jenkins DP, Walker GH (2010) Human factors in the design and evaluation of central control room operations. CRC Press, Boca Raton

Stanton NA, Rothrock L, Harvey C, Sorensen L (2015a) Investigating performance of command team structures in the NATO problemapproach space. IEEE Trans Hum-Mach Syst 45(6):702-713

Stanton NA, Rothrock L, Harvey C, Sorensen L (2015b) Investigating information-processing performance of different command team structures in the NATO Problem Space. Ergonomics 58(12):2078-2100

Stanton NA, Salmon PM, Walker GH, Hancock PA, Salas E (2017) State-of-science: situation awareness in individuals, teams and systems. Ergonomics 60(4):449-466

Stewart R, Stanton NA, Harris D, Baber C, Salmon P, Mock M, Kay A (2008) Distributed situation awareness in an airborne warning and control system: application of novel ergonomics methodology. Cogn Technol Work 10(3):221-229

Stone R, Caird-Daley A, Bessell K (2009) Sub Safe: a games-based training system for submarine safety and spatial awareness (Part 1). Virtual Real 13(1):3-12

Walker GH, Stanton NA, Salmon PM, Jenkins DP (2008) A review of sociotechnical systems theory: a classic concept for new command and control paradigms. Theor Issues Ergon Sci 9(6):479-499

Walker GH, Stanton NA, Salmon PM, Jenkins DP (2009) Command and control: the sociotechnical perspective. Ashgate, Aldershot

Walker GH, Stanton NA, Salmon PM, Jenkins DP, Rafferty L, Ladva D (2010) Same or different? Generalising from novices to experts in military command and control studies. Int J Ind Ergon 40(5):473-483

Zarnich RE 1999 A fresh look at broadband passive sonar processing. In: adaptive sensor array processing workshop, Office of Naval Research, p 99-104 